\title{
Type I IFN signature in childhood-onset systemic lupus erythematosus: a conspiracy of DNA- and RNA-sensing receptors?
}

\author{
M. Javad Wahadat', Iris L. A. Bodewes ${ }^{1}$, Naomi I. Maria', Cornelia G. van Helden-Meeuwsen', \\ Annette van Dijk-Hummelman², Eline C. Steenwijk', Sylvia Kamphuis ${ }^{2}$ and Marjan A. Versnel ${ }^{1 *}$
}

\begin{abstract}
Background: Childhood-onset systemic lupus erythematosus (CSLE) is an incurable multi-systemic autoimmune disease. Interferon type I (IFN-I) plays a pivotal role in the pathogenesis of SLE. The objective of this study was to assess the prevalence of the IFN-I signature and the contribution of cytosolic nucleic acid receptors to IFN-I activation in a cohort of primarily white cSLE patients.

Methods: The IFN-I score (positive or negative), as a measure of IFN-I activation, was assessed using real-time quantitative PCR (RT-PCR) expression values of IFN-I signature genes (IFI44, IFI44L, IFIT1, Ly6e, MXA, IFITM1) in CD14+ monocytes of cSLE patients and healthy controls (HCs). Innate immune receptor expression was determined by RT-PCR and flow cytometry. To clarify the contribution of RNA-binding RIG-like receptors (RLRs) and DNA-binding receptors (DBRs) to IFN-I activation, peripheral blood mononuclear cells (PBMCs) from patients were treated with BX795, a TANK-binding kinase 1 (TBK1) inhibitor blocking RLR and DBR pathways.

Results: The IFN-I signature was positive in 57\% of CSLE patients and 15\% of the HCs. Upregulated gene expression of TLR7, RLRs (IFIH1, DDX58, DDX60, DHX58) and DBRs (ZBP-1, IFI16) was observed in CD14+ monocytes of the IFN-I-positive cSLE patients. Additionally, RIG-I and ZBP-1 protein expression was upregulated in these cells. Spontaneous IFN-I stimulated gene (ISG) expression in PBMCs from cSLE patients was inhibited by a TBK1-blocker.

Conclusions: IFN-I activation, assessed as ISG expression, in CSLE is associated with increased expression of TLR7, and RNA and DNA binding receptors, and these receptors contribute to IFN-I activation via TBK1 signaling. TBK1-blockers may therefore be a promising treatment target for SLE.
\end{abstract}

Keywords: Interferon type I, Childhood-onset SLE, TLR7, Cytosolic nucleic receptors, TBK1

\section{Background}

Childhood-onset systemic lupus erythematosus (cSLE) is a lifelong multi-systemic autoimmune disease that shares disease pathogenesis with adult-onset SLE but in most studies is characterized by a more severe disease course and poorer prognosis [1-3]. Interferon type I (IFN-I) plays a central role in the pathogenesis of SLE [4-7]. Surprisingly, trials blocking exogenous IFN-I or its receptor have shown limited effectivity so far, possibly due

\footnotetext{
* Correspondence: m.versnel@erasmusmc.nl

'Department of Immunology, Erasmus MC, University Medical Centre

Rotterdam, 3015 CN Rotterdam, The Netherlands

Full list of author information is available at the end of the article
}

to our lack of knowledge of the pathways leading to IFN activation [8].

About half of patients with adult-onset SLE exhibit increased activation of IFN-I signaling or a so-called positive IFN-I signature $[4,5,9]$. This IFN-I signature is usually assessed by measuring IFN-I-stimulated gene expression. In a USA cohort of primarily non-white patients with cSLE with high disease activity, approximately $80-90 \%$ IFN-I activation has been reported [6, 10]. To our knowledge the prevalence of the IFN signature has not been studied in other cSLE cohorts.

The endosomal toll-like receptors (TLRs) 7 and 9 induce IFN expression in response to internalized RNAcontaining and DNA-containing immune complexes. 
Loss of the regulation of TLR7 and TLR9, both binding exogenous self-nucleic acids, has been linked to SLE disease pathogenesis in mouse models and in humans [11, 12]. In addition to the TLRs, induction of IFN-I expression can also be initiated by two cytosolic nucleicsensing receptor families, known as (i) the RIG-like receptors (RLRs) sensing RNA and (ii) the DNA-binding receptors (DBRs) (Fig. 1). In Sjögren's syndrome we recently observed upregulation of RLRs that may contribute to IFN type I positivity in this disease [13]. The DBRs, like IFI16 and ZBP-1/DAI, bind intracellular double-stranded DNA (dsDNA) [14, 15] and as a result initiate production of IFN-I. Interestingly, mutations in the RLRs, DBRs and their downstream signaling molecules lead to systemic IFN-I activation in diseases grouped as "type I interferonopathies" [16-18]. Patients with these diseases have similarities to the SLE disease phenotype, pointing towards a central role of these molecules in IFN activation and potentially in the pathogenesis of SLE [16-18].

The objective of this study was to determine the prevalence of the IFN-I signature in a cohort of primarily white patients with cSLE and address the potential contribution of cytosolic nucleic acid receptors to IFN activation.

\section{Methods}

\section{Patients and controls}

Twenty-three patients with cSLE fulfilling at least four of the American College of Rheumatology criteria were recruited at the outpatient clinic of the department of pediatric rheumatology of the Sophia Children's Hospital, Erasmus Medical Centre. Thirteen healthy controls (HCs), specifically checked for not having (viral) infections and not having family members with autoimmune diseases, were included. Patient characteristics are summarized in Table 1. The Medical Ethical Review Board of the Erasmus Medical Centre approved the study and written informed consent was obtained from all participants and their parents or legal guardians.

\section{Blood collection and isolation of monocytes and plasmacytoid dendritic cells}

Blood samples were collected in sodium-heparin tubes (Greiner Bio-One, Germany) followed by isolation of peripheral blood mononuclear cells (PBMCs) as described before [19]. PBMCs were thawed, centrifuged for $5 \mathrm{~min}\left(1500 \mathrm{rpm}, 4{ }^{\circ} \mathrm{C}\right)$ and resuspended in $100 \mu \mathrm{l} \mathrm{sort}-$ buffer (PBS pH 7.4, 2 mM EDTA $1 \mathrm{M}, 0.5 \%$ BSA). For membrane staining, cells were incubated for $15 \mathrm{~min}$ in the dark with anti-CD14 (APC/Cy7; Becton Dickinson Biosciences, San Diego, USA), anti-BDCA-4 (PE; Miltenyi Biotec, Bergisch Gladbach, Germany), antiCD123 (PE-Cy7; eBioscience, San Diego, USA), antiCD3 (PerCP-Cy5; Becton Dickinson Biosciences), and anti-CD19 (APC; Becton Dickinson Biosciences). Cells were sorted using a FACSAria III cell sorter (BD Bioscience) and analyzed using FlowJo Sofware (TreeStar Inc., Ashland, USA).

\section{RT-PCR}

RNAeasy columns (Qiagen, Hilden, Germany) were used to isolate total RNA followed by reverse-transcription to cDNA using a High-Capacity Reverse Transcription Kit (Applied Biosystems, Foster City, USA). RT-PCR analysis was performed using a 7900HT Fast Real-Time PCR System using predesigned primer sets (Applied Biosystems). Data were normalized to the expression of the household gene $A B L$ to calculate the relative expression. $A B L$ was previously described as a reliable household gene for myeloid cells [20]. $A B L$ was not differentially expressed upon stratification of samples

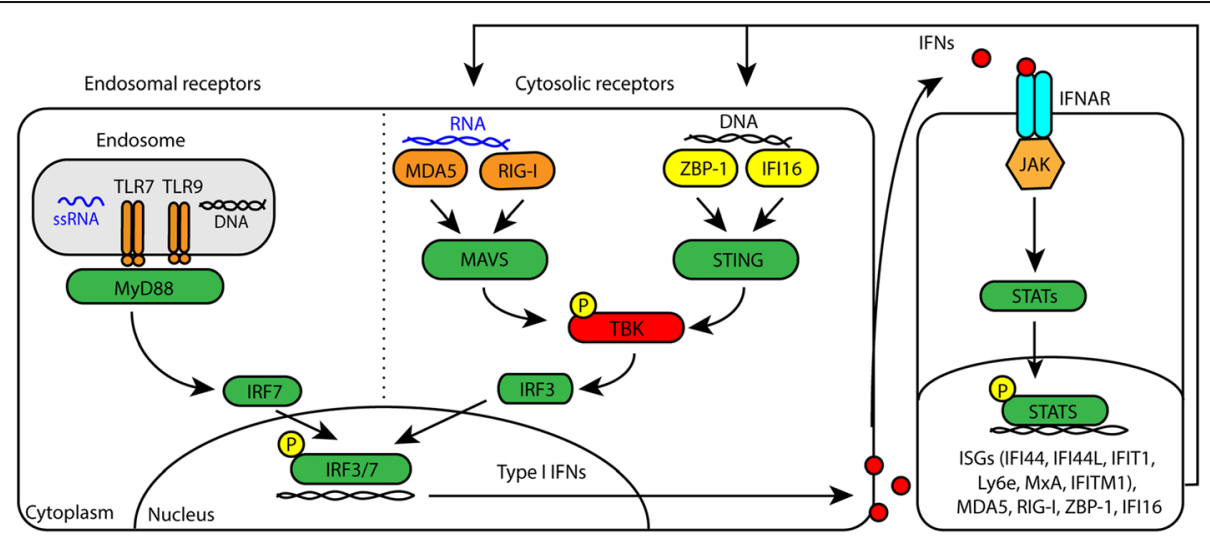

Fig. 1 Simplified scheme of the induction of interferon (IFN) type I production by three signaling pathways: (1) endosomal receptors toll-like receptor (TLR)7 and TLR9; (2) RNA-binding cytosolic receptors MDA5 and RIG-l; and (3) DNA-binding receptors ZBP1 and IFI16. These pathways contribute to the activation of interferon regulatory factors (IRFs), which induce the expression of type I IFNs. Binding of IFN to cells that express the interferon alpha receptor (IFNAR) activates a cascade that leads to the expression of various IFN-stimulated genes (ISGs), known as the IFN type I signature 
Table 1 Patient and control characteristics

\begin{tabular}{|c|c|c|c|c|}
\hline & \multirow[b]{2}{*}{$\mathrm{HC}(n=13)$} & \multicolumn{2}{|l|}{ CSLE } & \\
\hline & & IFNpos $(n=13)$ & IFNneg $(n=10)$ & \\
\hline \multicolumn{5}{|l|}{ Demographics } \\
\hline \multicolumn{5}{|l|}{ Ethnicity } \\
\hline White & 13/13 (100\%) & $9 / 13(69 \%)$ & $7 / 10(70 \%)$ & $\mathrm{Ns}^{\mathrm{c}}$ \\
\hline Non-white & 0/13 (0\%) & 4/13 (31\%) & $3 / 10(30 \%)$ & $N s^{c}$ \\
\hline \multicolumn{5}{|l|}{ Gender } \\
\hline Male (\%) & $3 / 13(23 \%)$ & $2 / 13(15 \%)$ & $2 / 10(20 \%)$ & $\mathrm{Ns}^{\mathrm{c}}$ \\
\hline Female (\%) & 10/13 (77\%) & $11 / 13(85 \%)$ & $8 / 10(80 \%)$ & $\mathrm{Ns}^{\mathrm{c}}$ \\
\hline $\begin{array}{l}\text { Median age } \\
\text { (years) }\end{array}$ & $22(15 \pm 25)$ & $15.8(4.8 \pm 18.2)$ & $15.1(9.3 \pm 17.5)$ & $\mathrm{Ns}^{\mathrm{a}}$ \\
\hline $\begin{array}{l}\text { Disease duration } \\
\text { (years) }\end{array}$ & - & $0.85(0 \pm 3.4)$ & $1.5(0 \pm 4.7)$ & $\mathrm{Ns}^{\mathrm{b}}$ \\
\hline SELENA-SLEDAI & - & $4(0 \pm 20)$ & $3(0 \pm 13)$ & $\mathrm{Ns}^{\mathrm{b}}$ \\
\hline \multicolumn{5}{|l|}{ Laboratory parameters } \\
\hline ANA & - & $12 / 13(92 \%)$ & 9/10 (90\%) & $\mathrm{Ns}^{\mathrm{c}}$ \\
\hline Anti-ds-DNA & - & 4/13 (31\%) & $2 / 10(20 \%)$ & $\mathrm{Ns}^{\mathrm{c}}$ \\
\hline Anti-Ro52/Ro60 & - & 6/13 (46\%) & 0/10 (0\%) & $p=0.019^{c}$ \\
\hline Anti-La & - & $2 / 13(15 \%)$ & 0/10 (0\%) & $\mathrm{Ns}^{\mathrm{c}}$ \\
\hline Anti-RNP & - & $5 / 13(31 \%)$ & 0/10 (0\%) & $p=0.046^{c}$ \\
\hline $\mathrm{C} 3(\mathrm{~g} / \mathrm{l})$ & - & $0.89(0.3 \pm 1.27)$ & $1.1(0.77 \pm 1.72)$ & $p=0.014^{b}$ \\
\hline $\mathrm{C} 4(\mathrm{~g} / \mathrm{l})$ & & $0.16(0.02 \pm 0.2)$ & $0.19(0.1 \pm 0.37)$ & $p=0.049^{b}$ \\
\hline $\lg G(g / l)$ & - & $10.3(7.1 \pm 27.6)$ & $9.6(8.4 \pm 28)$ & $\mathrm{Ns}^{\mathrm{b}}$ \\
\hline \multicolumn{5}{|l|}{ Medication (\%) } \\
\hline Hydroxychloroquine & - & 10/13 (77\%) & $10 / 10(100 \%)$ & $\mathrm{Ns}^{\mathrm{c}}$ \\
\hline Mycofenolaatmofetil & & 3/13 (23\%) & $6 / 10(60 \%)$ & $\mathrm{Ns}^{\mathrm{c}}$ \\
\hline Prednisone & - & 6/13 (46\%) & $5 / 10(50 \%)$ & $\mathrm{Ns}^{\mathrm{c}}$ \\
\hline Other medication & - & $5 / 13(38 \%)$ & $5 / 10(50 \%)$ & $\mathrm{Ns}^{\mathrm{c}}$ \\
\hline
\end{tabular}

Data are presented as median (IQR) or as number (\%) of patients according to data distribution. Non-white ethnicity $=$ Hindu and Suriname.

SELENA Safety of Estrogens in Lupus National Assessment, SLEDAI Systemic Lupus Erythematosus Disease Activity Index, ANA antinuclear antibody, Anti-RNP antibodies to ribonucleoprotein, C complement, IgG immunoglobulin, CSLE childhood-onset systemic lupus erythematosus, IFNpos interferon (IFN) signature positive, IFNneg IFN signature negative, $H C$ healthy control, Ns not significant

${ }^{a}$ Groups compared using the Kruskal-Wallis test (three groups)

${ }^{b}$ Groups compared using the Mann-Whitney U test (two groups)

'Groups compared using Fisher's exact test (categorical data)

according to the IFN-stimulated gene expression scores (unpublished results). Fold-change values were determined from normalized cycle threshold (CT) values using the $2^{\wedge}-\Delta \Delta C T$ method (User Bulletin, Applied Biosystems).

\section{Monocyte IFN type I signature and MxA protein assessment}

Principle component analysis showed a subset of 6 genes (IFI44, IFI44L, IFIT1, Ly6e, MxA, and IFITM1) to explain more than $95 \%$ of the total variance of the 11 IFN-I-inducible genes tested. As the expression of the six IFN-I-inducible genes was not normally distributed, log expression values were log-transformed and IFN scores were calculated as described previously [19]. The mean and standard deviation (SD) of each IFN-inducible gene in the $\mathrm{HC}$ group was used to standardize expression levels of each gene for each study subject. Patients with cSLE were stratified into patients positive for the IFN-I signature (IFNpos; IFN score $\geq 10$ ) and patients negative for the signature (IFNneg; IFN score $<10)$. Flow cytometric analysis of MxA on CD14+ monocytes and the MxA-EIA was performed as previously described [21].

\section{Flow cytometric analysis of RLRs and DBR}

Membranes were stained as described above with additional AnnexinV-BV421 staining (Milteny Biotec). Subsequently, cells were fixed and permeabilized by a permeabilization buffer set (eBioscience) with $1 \%$ paraformaldehyde, $0.5 \%$ saponin and stained with either rabbit anti-Mx1 (ProteinTech, Chicago, USA), rabbit anti-MDA5 (Abcam, Cambridge, UK), rabbit antiDDX58 (Abcam), rabbit anti-IFI16 (Abcam) and rabbit anti-ZBP1 (Thermofischer, Rockford, USA)) and incubated in the dark for 45 min on ice. As a secondary antibody, chicken anti-rabbit-AF488 (Invitrogen, Carlsbad, USA) was used. Unstained cells and isotype-matched controls (Becton Dickinson Biosciences) were used to assess antibody specificity. Analysis was performed as previously described [21].

\section{In vitro stimulation bioassays}

PBMCs were seeded at a concentration of $2 \times 10 \mathrm{E} 6 /$ $250 \mu \mathrm{L}$, and starved during 1 hour at $37^{\circ} \mathrm{C}$ in RPMI with $0.5 \%$ fetal calf serum, $0.05 \% \mathrm{P} / \mathrm{S}$. Cells were subsequently stimulated for 5 hours with $0.5 \mu \mathrm{g} / \mathrm{mL}$ Imiquimod (R837, IQ; InvivoGen, San Diego, USA), in the presence or absence of specific inhibitors for TANK-binding kinase 1 (TBK1)/IKKe (BX795, $1 \mu \mathrm{M}$, InvivoGen), TLR7 (IRS 661, $2 \mu \mathrm{M}$, TIB-Molbiol, Berlin, Germany) and TLR7 + TLR9 (ALX-746-255, $5 \mu$ M, Enzo Life Sciences, Lausen, Switzerland).

\section{Statistical analysis}

The non-parametric Mann-Whitney U (two groups) and Kruskal-Wallis (three groups) tests were used to analyze comparisons between medians. The paired $t$ test was used to compare means of paired data. Fisher's exact test was used to compare categorical data. Spearman's rho (rs) coefficient was calculated to assess correlation. Values of $p<0.05$ were considered statistically significant. Graphpad Prism 5.0 (Graphpad Software, La Jolla, CA, USA) was used to design the graphs and IMB SPSS 20.0 (SPSS, Chicago, IL, USA) was used for the statistical analysis.

\section{Results}

Prevalence of the IFN-I signature in CSLE

The IFN-I score was calculated for each subject by summing the standardized expression levels of the six IFN-I 
inducible genes. As there was a bimodal distribution of IFN-inducible genes in patients with CSLE, we set the threshold at an IFN-I score of 10. Using this threshold, $57 \%(13 / 23)$ of the patients with cSLE and $15 \%$ of the HCs $(2 / 13)$ were IFN-I-positive (Fig. 2a). Previously we found that MxA protein expression assessed using flow cytometry on $\mathrm{CD}_{1} 4^{+}$monocytes and a whole blood enzyme immunoassay are applicable biomarkers for systemic IFN-I activation in Sjögren's syndrome [21]. Both assays were tested simultaneously on the same PBMC samples. Results from these assays confirmed the results obtained by IFN-induced gene expression analysis (Fig. 2b, c).

\section{Increased expression of TLR7, RLR and DBR in CD14+ monocytes of cSLE}

Upon ligand binding the TLRs, RLRs and DBRs all initiate IFN-I production (Fig. 1). The gene expression of TLR7, TLR9, four RLRs and two DBRs was assessed in CD14+ monocytes from patients with cSLE stratified into IFNpos and IFNneg patients. TLR7 expression was significantly upregulated in IFNpos patients compared to HCs (Fig. 3a). There were no significant differences in TLR7 expression between IFNneg and IFNpos patients or between IFNneg patients and HCs. In addition, TLR9 expression did not differ between the groups.

The expression levels of the RLRs IFIH1, DHX58, DDX58 and DDX60 and the DBRs ZBP-1 and IFI16 were significantly upregulated in IFNpos patients compared to IFNneg patients and HCs (Fig. 3b, c). There was no significant difference between IFNneg patients and the HCs in RLR or DBR expression levels. Furthermore, expression levels of the RLRs and DBRs were positively correlated with IFN scores (Additional file 1).
Increased RIG-I and ZBP-1 protein levels in CSLE

To study protein expression of RLRs and DBRs we performed flow cytometric analysis of MDA5, RIG-I, IFI-16 and ZBP-1 expression in CD14+ monocytes from IFNpos and IFNneg patients with cSLE and from HCs. The gating strategy and a representative figure are depicted in Additional file 2. RIG-I and ZBP-1 protein expression was significantly upregulated in $\mathrm{CD} 14+$ monocytes from IFNpos patients with cSLE compared to HCs (Fig. 4). There were no significant differences in MDA5 and IFI16 protein levels in CD14+ monocytes from patients and HCs. Plasmacytoid dendritic cells (pDCs) are known to upregulate RLRs and DBRs upon IFN-I activation. In pDCs from IFNpos patients with cSLE the expression of ZBP-1 and IFI16 was significantly upregulated (Additional file 3 ).

\section{TBK1/IKK $\varepsilon$ inhibitor blocks IFN-I activation in PBMCs from patients with CSLE}

To study the contribution of the RLR and DBR pathways to IFN-I activation in cSLE we blocked these pathways using a TBK1/IKKe inhibitor (BX795). A titration of BX795 is shown in Additional file 4. TLRs were blocked with inhibitors for TLR7 (IRS661) [13] and TLR7 + TLR9 (ALX-746-255). As a positive control for the effectivity of the blockers, HC PBMCs were stimulated with the TLR7-agonist imiquimod (IQ) to induce IFN-I positivity followed by incubation with these inhibitors (Additional file 5). PBMCs from IFNpos and IFNneg patients with CSLE, without any additional stimulation, exhibited increased spontaneous IFN-stimulated gene expression compared to $\mathrm{HCs}$ as determined by MxA expression (Fig. 5). Incubation with the TBK1/IKKe inhibitor completely reduced the spontaneous IFN-I stimulated gene
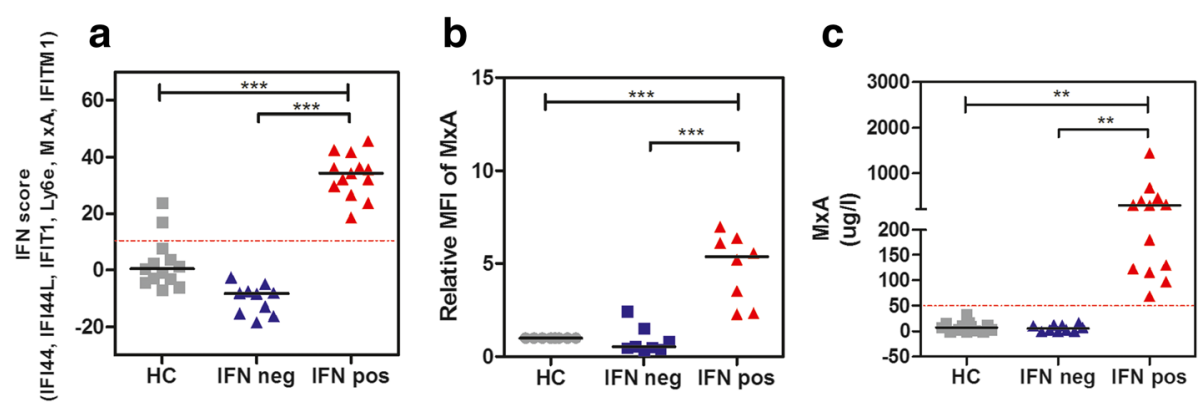

Fig. 2 a Prevalence of the interferon (IFN) type I signature in patients with childhood-onset systemic lupus erythematosus (CSLE). Dotted line indicates the cutoff value of 10 for discrimination between IFN-negative (IFNneg) and IFN-positive (IFNpos) subjects. b Relative MxA expression was calculated as (MxA-specific staining patient (MFI)-isotype control patient (MFI))/(MxA-specific staining healthy control (HC) (MFI)-isotype control HC (MFI)). MXA is shown for HCs, IFN neg and IFN pos patients with cSLE. c MXA levels (ug/l) determined by MxA-enzyme immunoassays (EIA) in whole-blood lysates of HCs and patients with CSLE. Dotted line indicates the cutoff value of 50 for discrimination between IFN neg and IFN pos subjects. Every symbol represents one subject; horizontal lines describe the medians; groups were compared using one-way analysis of variance (three groups): ${ }^{*} p<0.05 ;{ }^{* *} p<0.01 ;{ }^{* * *} p<0.001 ;{ }^{* * *} p<0.0001$ 

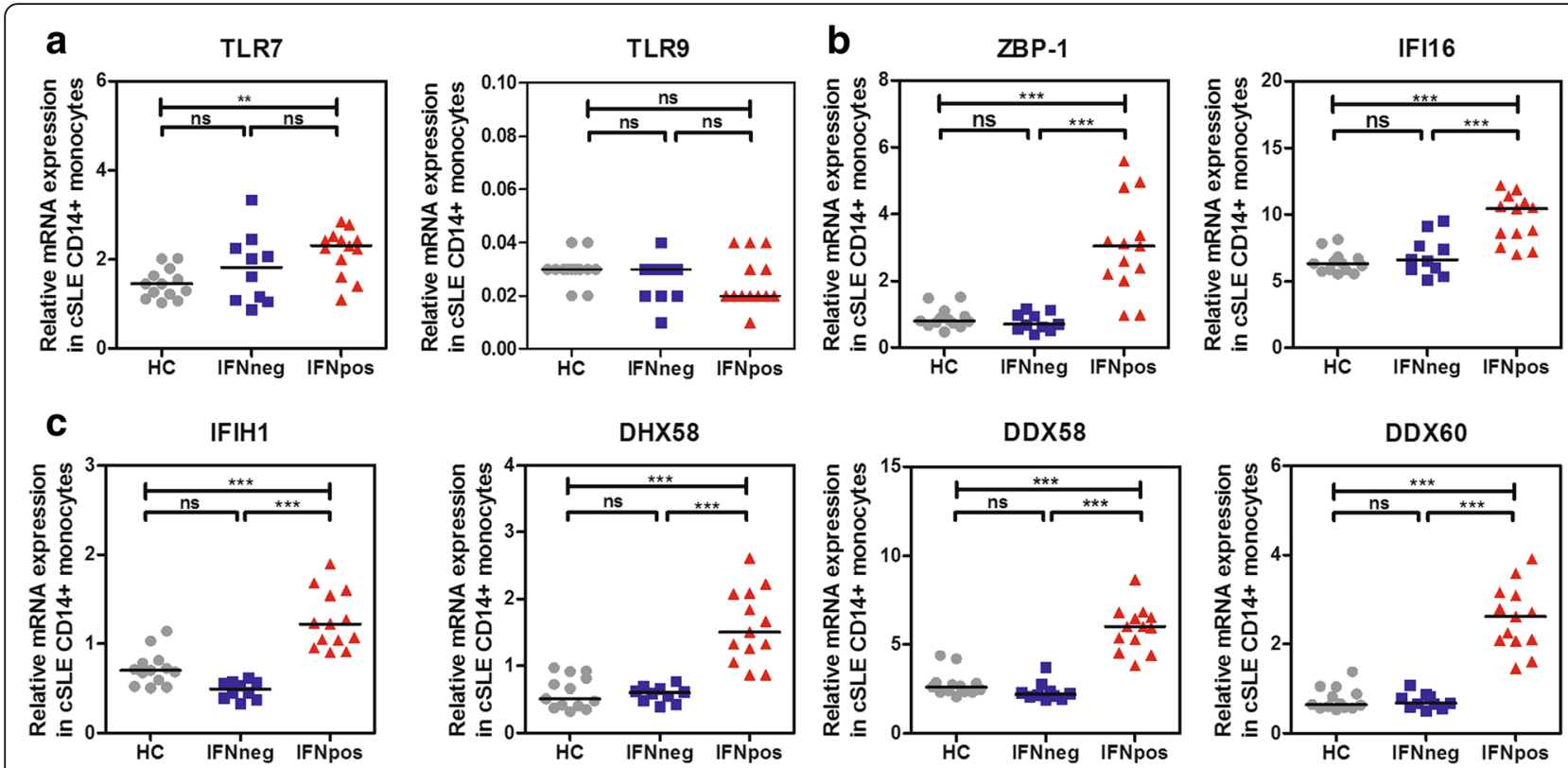

Fig. 3 Upregulation of toll-like receptor 7 (TLR7) and cytosolic RNA-binding and DNA-binding receptors in interferon (IFN) type I positive (IFNpos) patients with childhood-onset systemic lupus erythematosus (CSLE). Relative mRNA gene expression of TLR7 and TLR9 (a), ZBP-1 and IFI16 (b) and IFIH1, DHX58, DDX58, and DDX60 (c) in CD14+ monocytes from patients with CSLE $(n=23)$ and healthy controls (HCs) $(n=13)$. Each symbol represents an individual sample; horizontal lines represent medians. One-way analysis of variance was used to compare the three groups: Ns, not significant; ${ }^{*} p<0.05 ;{ }^{* *} p<0.01 ;{ }^{* * *} p<0.001 ;{ }^{* * *} p<0.0001$. IFNneg IFN-negative patients, IFNpos IFN-positive patients

expression in cells from patients with cSLE. Inhibition of TLR7 or TLR7 + TLR9 had no effect on the intrinsic spontaneous IFN activation in PBMCs of IFNneg and IFNpos patients with cSLE (Fig. 5).

\section{Discussion}

This study shows increased expression of TLR7 and the cytosolic receptors of the RLR and DBR families in monocytes of IFN-I-positive patients with cSLE. Blocking of the RLR and DBR signaling pathway downregulated IFN-Istimulated gene expression indicating a contribution of these receptors to systemic IFN-I activation in SLE.
In our cohort of patients with cSLE, $57 \%$ had a positive IFN-I signature. This is in line with our earlier observations in a cohort of patients with adult-onset SLE [9]. Previous studies report that $80-90 \%$ of patients with cSLE are IFN-I-positive; these were primarily non-white patients with relatively high disease activity $[6,10]$. In contrast, our cohort consists of mainly white patients with CSLE of low disease activity, which may account for at least part of the difference in prevalence, as the presence of IFN-I signature is related to disease activity [19]. As in the other cSLE cohorts, most patients with cSLE in our cohort used anti-inflammatory medication. The presence of an IFN-I signature in patients receiving

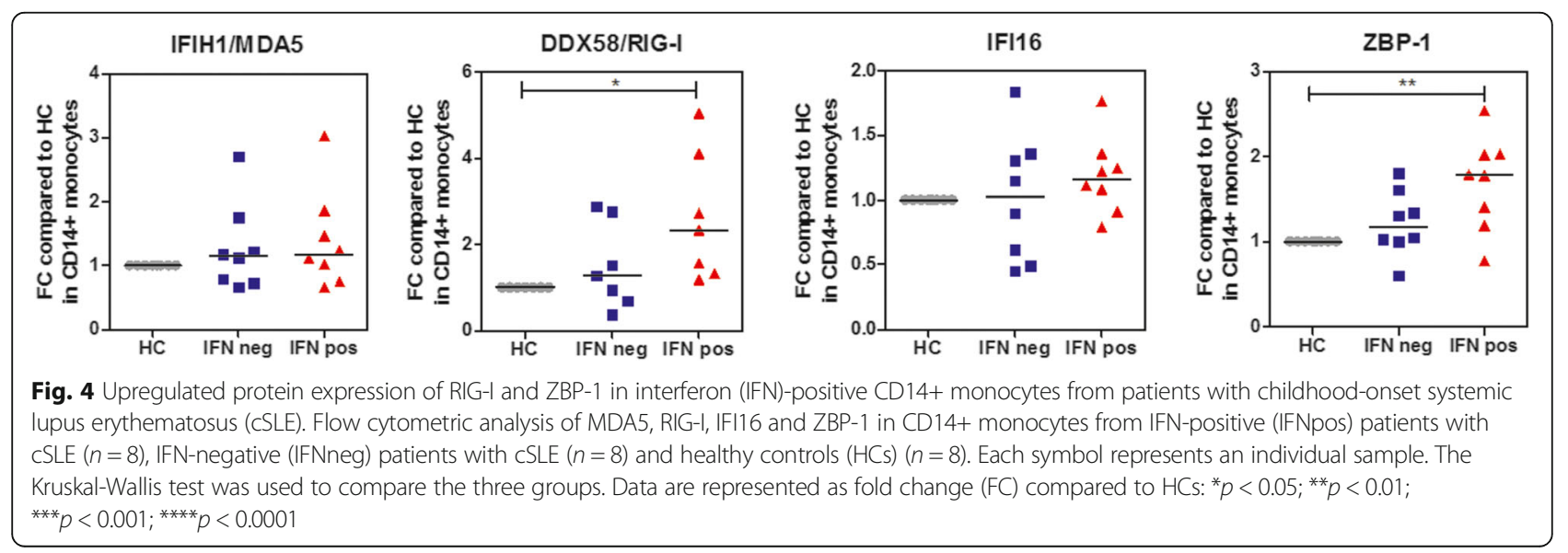




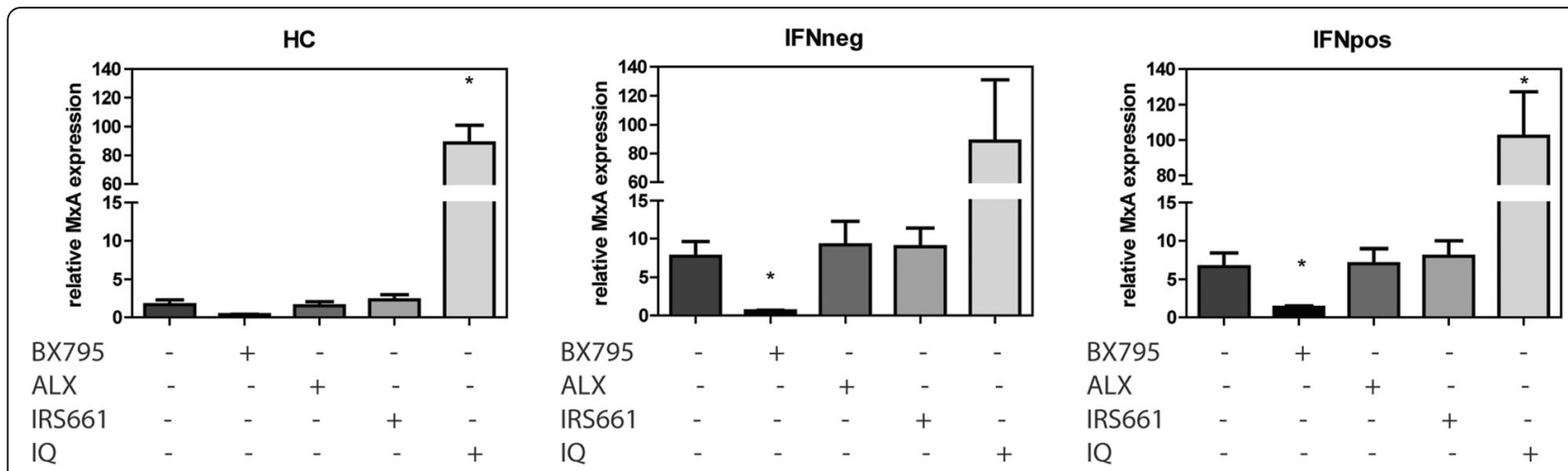

Fig. 5 TANK-binding kinase 1 (TBK1)/inhibitor of nuclear factor kappa-B kinase subunit epsilon (IKKE) inhibits interferon (IFN) type I activation in peripheral blood mononuclear cells (PBMCs) from patients with childhood-onset lupus erythematosus (cSLE). Relative MxA gene expression after 5-h culture of PBMCs from healthy controls (HCs), IFN-negative (IFNneg) or IFN-positive (IFNpos) patients with cSLE stimulated with imiquimod (IQ) (1 $\mu \mathrm{g} /$

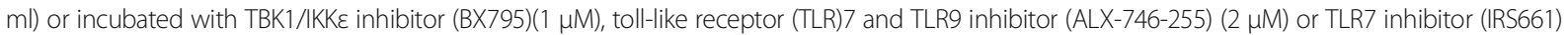
$(5 \mu \mathrm{M})$. Unstimulated cells and cells without inhibitors added were cultured in starvation medium and used as control for baseline IFN activation. Gene expression data are presented as means \pm SEM of four independent experiments ( $n=5$ per group). Means were compared to starvation medium using the paired $t$ test: ${ }^{*} p<0.05 ;{ }^{* *} p<0.01 ;{ }^{* * *} p<0.001 ;{ }^{* * * *} p<0.0001$

medication indicates that current treatments are not able or are only partly able to downregulate IFN-I stimulated gene expression.

Upon stratification of IFNpos and IFNneg patients with cSLE, we identified upregulation of TLR7 in IFNpositive cSLE. This supports a role for TLR7 in the induction of IFN-I activation in SLE as has been demonstrated in animal models [22, 23]. Interestingly, a Mexican cohort of patients with cSLE showed that the gene dosage of TLR7 is an important risk factor for cSLE susceptibility [24]. In our ex vivo experiments, TLR7 or TLR7 + TLR9 inhibitors did not decrease IFN-I activation in patients with cSLE. This is likely due to the short culture period of 5 hours, which does not allow formation of nucleic acids containing immune complexes, which are required for TLR7/9-driven IFN induction. Therefore, the exact role of TLRs in comparison with cytosolic receptors remains to be established.

The expression of cytosolic receptors belonging to the RLRs and DBRs, was upregulated in IFNpos patients with cSLE compared to HCs and IFNneg patients. Accumulating evidence indicates an important role for aberrancies in these receptors and their downstream signaling molecules in monogenic diseases with clinical similarities to SLE $[16,17]$. Interestingly, a recent study showed correlation between IFN-I activation and the expression of an endogenous virus-like genomic repeat element L1 in kidney tissue of patients with lupus nephritis. As such an L1 element activates RLRs this supports a role of this receptor family in SLE [25].

The potential contribution of RLRs and DBRs to IFN-I activation was also supported by our ex vivo experiments showing clearly decreased IFN-I stimulated gene expression in all patients with cSLE upon ex vivo blocking of TBK1. TBK1 is at the crossroad downstream of the RLR and DBR signaling pathways. Interestingly, TBK1 upregulation has been observed in PBMCs from patients with SLE [26] and inhibition of TBK1 activity suppresses IFN-I induced autoimmunity in a mouse model of SLE [27]. Blockade of TBK1/ IKK $\varepsilon$ with BX795 was also found to inhibit IFN-Istimulated gene expression in PBMCs from a patient with a gain-of-function mutation in STING, which resulted in over-secretion of IFN-I [28]. In our ex vivo experiments, PBMCs from IFNneg patients also had higher spontaneous intrinsic IFN-I-stimulated gene expression, which could be decreased by TBK1 inhibition with BX795. This is probably due to stimulation of the IFN-I-inducing pathways by the presence of more dead cells and cell material, which we always observe in samples from patients with SLE compared to controls, despite the same isolation procedure. This is in line with data showing greater vulnerability of the cells in SLE [29].

To date, inhibiting IFN activation by blocking IFN-I receptor (IFNAR) by biological agents so far has had encouraging results but the treatment is only effective in a subset of the patients [30]. More upstream interference using TBK1 inhibitors to prevent the induction of IFN expression might be a better approach. With TBK1 as an upstream signaling hub inducing IFN-I expression and more than 20 patented TBK1 inhibitors already developed, a novel treatment target for clinical applications might enter the field. Compared to most other biological agents, small-molecule TBK1 inhibitors have two advantages: (1) the inhibitors can be taken orally and (2) they are expected to have fewer side effects due to the high specificity [27]. 
This study has limitations. All patients are receiving treatment, which could have affected the IFN-I activation and due to lack of reliable assays to detect systemic IFN-I activation in serum, the IFN-induced gene expression was used.

Several studies in PBMCs of adult SLE patients describe a difference between IFN- $\alpha$ or IFN- $\beta$ induced genes [7, 31]. We did not make this distinction in our study as we used monocytes and these IFNsubtype-specific-induced genes can differ per cell type. Additionally, the treatment presently tested in clinical trials is focused on blocking the IFNAR, which binds both IFN- $\alpha$ and IFN- $\beta$.

Furthermore, we studied mRNA and protein expression from monocytes but the patient's pDCs were only studied by flow cytometry. However, monocytes are considered important responders to RLR and DBR triggering and the ex vivo cultures of PBMCs from patients simulate the in vivo situation. The TBK1 inhibitor used also inhibits IKKe. Therefore a role of IKKe in the IFN-I activation in SLE cannot be excluded.

\section{Conclusions}

Overall, the IFN-I signature was present in 57\% of patients with cSLE and was associated with increased expression of TLR7 and cytosolic nucleic acid binding receptors. These RLRs and DBRs contributed to the spontaneous ex vivo IFN-I-stimulated gene expression via TBK1 signaling. Inhibitors of TBK1 are therefore a promising treatment target for SLE.

\section{Additional files}

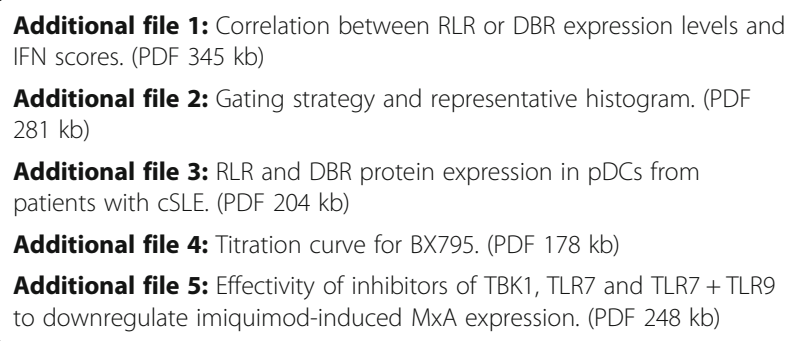

\section{Abbreviations}

BSA: Bovine serum albumin; CSLE: Childhood-onset systemic lupus erythematosus; CT: Cycle threshold; DBR: DNA-binding receptor; HC: Healthy controls; IFNAR: IFN type I receptor; IFN-I: Interferon type I; IKKE: Inhibitor of nuclear factor kappa-B kinase subunit epsilon; IQ: Imiquimod; PBMCs: Peripheral blood mononuclear cells; PBS: Phosphate-buffered saline; pDCs: Plasmacytoid dendritic cells; RLR: RIG-like receptor; RT-PCR: Real-time quantitative PCR; SD: Standard deviation; TBK1: TANK-binding kinase 1; TLR: Toll-like receptor

\section{Acknowledgements}

The research for this article was (partly) performed within the framework of the Erasmus Postgraduate School Molecular Medicine. The authors thank all the patients with CSLE and the HCs for taking part in this study. Furthermore, the authors thank A. van Loef, L. Xue and I. Brouwers-Haspels for assistance with sample collection and data acquisition.

Funding

This study was supported by grants from the Dutch Arthritis Foundation (Reumafonds); 14-3-404 and 10-1-401.

\section{Availability of data and materials}

The data supporting the conclusions of this article are included within the article and its additional files.

\section{Authors' contributions}

MJW was involved in conception and study design, clinical and laboratory data acquisition and monitoring, analysis and interpretation of data and drafting and revising the article. ILAB was involved in study design and together with $\mathrm{CvH}-\mathrm{M}$ was involved in laboratory data acquisition, analysis of data and revising the manuscript. NIM was involved in conception and study design, clinical and laboratory data acquisition and monitoring, interpretation of the first analysis and revising the manuscript. ECS was involved in data acquisition and analysis. AvD-H was involved in clinical data acquisition and sample collection. SSMK and MAV were involved in conception and study design, data monitoring and interpretation and revising the article. All authors read and approved the final manuscript.

\section{Authors' information}

Not applicable.

\section{Ethics approval and consent to participate}

The Medical Ethical Review Board of the Erasmus MC Rotterdam approved the study and written informed consent was obtained from all participants and their parents or legal guardians.

\section{Consent for publication}

Not applicable.

\section{Competing interests}

The authors declare no competing interests.

\section{Publisher's Note}

Springer Nature remains neutral with regard to jurisdictional claims in published maps and institutional affiliations.

\section{Author details}

${ }^{1}$ Department of Immunology, Erasmus MC, University Medical Centre Rotterdam, 3015 CN Rotterdam, The Netherlands. ${ }^{2}$ Department of Pediatric Rheumatology, Sophia Children's Hospital, Erasmus MC, University Medical Centre, Rotterdam, The Netherlands.

Received: 31 August 2017 Accepted: 20 December 2017

Published online: 10 January 2018

\section{References}

1. Tsokos GC. Systemic lupus erythematosus. N Engl J Med. 2011;365(22):211021.

2. Livingston B, Bonner A, Pope J. Differences in clinical manifestations between childhood-onset lupus and adult-onset lupus: a meta-analysis. Lupus. 2011;20(13):1345-55.

3. Kamphuis S, Silverman ED. Prevalence and burden of pediatric-onset systemic lupus erythematosus. Nat Rev Rheumatol. 2010;6(9):538-46.

4. Baechler EC, Batliwalla FM, Karypis G, Gaffney PM, Ortmann WA, Espe KJ, Shark KB, Grande WJ, Hughes KM, Kapur V, et al. Interferon-inducible gene expression signature in peripheral blood cells of patients with severe lupus. Proc Natl Acad Sci U S A. 2003;100(5):2610-5.

5. Bennett L, Palucka AK, Arce E, Cantrell V, Borvak J, Banchereau J, Pascual V. Interferon and granulopoiesis signatures in systemic lupus erythematosus blood. J Exp Med. 2003;197(6):711-23.

6. Chaussabel D, Quinn C, Shen J, Patel P, Glaser C, Baldwin N, Stichweh D, Blankenship D, Li L, Munagala I, et al. A modular analysis framework for blood genomics studies: application to systemic lupus erythematosus. Immunity. 2008;29(1):150-64. 
7. Chiche L, Jourde-Chiche N, Whalen E, Presnell S, Gersuk V, Dang K, Anguiano E, Quinn C, Burtey S, Berland Y, et al. Modular transcriptional repertoire analyses of adults with systemic lupus erythematosus reveal distinct type I and type || interferon signatures. Arthritis Rheumatol. 2014; 66(6):1583-95.

8. Oon S, Wilson NJ, Wicks I. Targeted therapeutics in SLE: emerging strategies to modulate the interferon pathway. Clin Transl Immunol. 2016;5(5):e79.

9. Brkic Z, Corneth OB, van Helden-Meeuwsen CG, Dolhain RJ, Maria NI, Paulissen SM, Davelaar N, van Hamburg JP, van Daele PL, Dalm VA, et al. Thelper 17 cell cytokines and interferon type I: partners in crime in systemic lupus erythematosus? Arthritis Res Ther. 2014;16(2):R62.

10. Banchereau R, Hong S, Cantarel B, Baldwin N, Baisch J, Edens M, Cepika AM, Acs $P$, Turner J, Anguiano $E$, et al. Personalized immunomonitoring uncovers molecular networks that stratify lupus patients. Cell. 2016;165(3): 551-65.

11. Takeda K, Akira S. Toll-like receptors in innate immunity. Int Immunol. 2005; 17(1):1-14.

12. Christensen SR, Shupe J, Nickerson K, Kashgarian M, Flavell RA, Shlomchik MJ. Toll-like receptor 7 and TLR9 dictate autoantibody specificity and have opposing inflammatory and regulatory roles in a murine model of lupus. Immunity. 2006;25(3):417-28.

13. Maria NI, Steenwijk EC, ljpma AS, van Helden-Meeuwsen CG, Vogelsang P, Beumer W, Brkic Z, van Daele PLA, van Hagen PM, van der Spek PJ, et al. Contrasting expression pattern of RNA-sensing receptors TLR7, RIG-I and MDA5 in interferon-positive and interferon-negative patients with primary Sjögren's syndrome. Ann Rheum Dis. 2016;76(4):721-30.

14. Takaoka A, Wang Z, Choi MK, Yanai H, Negishi H, Ban T, Lu Y, Miyagishi M, Kodama T, Honda K, et al. DAI (DLM-1/ZBP1) is a cytosolic DNA sensor and an activator of innate immune response. Nature. 2007:448(7152):501-5.

15. Unterholzner L, Keating SE, Baran M, Horan KA, Jensen SB, Sharma S, Sirois CM, Jin T, Latz E, Xiao TS, et al. IFI16 is an innate immune sensor for intracellular DNA. Nat Immunol. 2010;11(11):997-1004.

16. Rice $\mathrm{Gl}$, del Toro Duany $\mathrm{Y}$, Jenkinson $\mathrm{EM}$, Forte $\mathrm{GM}$, Anderson $\mathrm{BH}$, Ariaudo G, Bader-Meunier B, Baildam EM, Battini R, Beresford MW, et al. Gain-offunction mutations in $\mathrm{FIH1}$ cause a spectrum of human disease phenotypes associated with upregulated type I interferon signaling. Nat Genet. 2014;46(5):503-9.

17. Funabiki M, Kato H, Miyachi $Y$, Toki $H$, Motegi $H$, Inoue M, Minowa O, Yoshida A, Deguchi K, Sato H, et al. Autoimmune disorders associated with gain of function of the intracellular sensor MDA5. Immunity. 2014;40(2):199-212.

18. Crow YJ. Type I, interferonopathies: a novel set of inborn errors of immunity. Ann NY Acad Sci. 2011;1238:91-8.

19. Brkic Z, Maria NI, van Helden-Meeuwsen CG, van de Merwe JP, van Daele PL, Dalm VA, Wildenberg ME, Beumer W, Drexhage HA, Versnel MA. Prevalence of interferon type I signature in CD14 monocytes of patients with Sjogren's syndrome and association with disease activity and BAFF gene expression. Ann Rheum Dis. 2013;72(5):728-35.

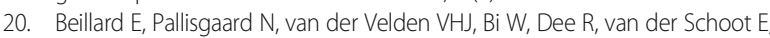
Delabesse E, Macintyre E, Gottardi E, Saglio G, et al. Evaluation of candidate control genes for diagnosis and residual disease detection in leukemic patients using 'real-time' quantitative reverse-transcriptase polymerase chain reaction (RQ-PCR) - a Europe against cancer program. Leukemia. 2003;17:2474.

21. Maria NI, Brkic Z, Waris M, van Helden-Meeuwsen CG, Heezen K, van de Merwe JP, van Daele PL, Dalm VA, Drexhage HA, Versnel MA. MXA as a clinically applicable biomarker for identifying systemic interferon type I in primary Sjogren's syndrome. Ann Rheum Dis. 2014;73(6):1052-9.

22. Marshak-Rothstein A. Toll-like receptors in systemic autoimmune disease. Nat Rev Immunol. 2006;6(11):823-35.

23. Desnues B, Macedo AB, Roussel-Queval A, Bonnardel J, Henri S, Demaria O, Alexopoulou L. TLR8 on dendritic cells and TLR9 on B cells restrain TLR7mediated spontaneous autoimmunity in C57BL/6 mice. Proc Natl Acad Sci U S A. 2014;111(4):1497-502.

24. Garcia-Ortiz H, Velazquez-Cruz R, Espinosa-Rosales F, Jimenez-Morales S, Baca V, Orozco L. Association of TLR7 copy number variation with susceptibility to childhood-onset systemic lupus erythematosus in Mexican population. Ann Rheum Dis. 2010;69(10):1861-5.

25. Mavragani CP, Sagalovskiy I, Guo Q, Nezos A, Kapsogeorgou EK, Lu P, Liang Zhou J, Kirou KA, Seshan SV, Moutsopoulos HM, et al. Expression of long interspersed nuclear element 1 retroelements and induction of type i interferon in patients with systemic autoimmune disease. Arthritis Rheumatol. 2016;68(11):2686-96.
26. Becker AM, Dao KH, Han BK, Kornu R, Lakhanpal S, Mobley AB, Li QZ, Lian Y, Wu T, Reimold AM, et al. SLE peripheral blood B cell, T cell and myeloid cell transcriptomes display unique profiles and each subset contributes to the interferon signature. PLoS One. 2013;8(6):e67003.

27. Hasan M, Yan N. Therapeutic potential of targeting TBK1 in autoimmune diseases and interferonopathies. Pharmacol Res. 2016;111:336-42.

28. Frémond $\mathrm{M}-\mathrm{L}$, Uggenti $\mathrm{C}$, Van Eyck L, Melki I, Bondet V, Kitabayashi N, Hertel C, Hayday A, Neven B, Rose Y, et al. Brief report: blockade of TANK-binding kinase 1/IKKE inhibits mutant stimulator of interferon genes (STING)mediated inflammatory responses in human peripheral blood mononuclear cells. Arthritis Rheumatol. 2017;69(7):1495-501.

29. Colonna L, Lood C, Elkon KB. Beyond apoptosis in lupus. Curr Opin Rheumatol. 2014;26(5):459-66.

30. Furie R, Khamashta M, Merrill JT, Werth VP, Kalunian K, Brohawn P, Illei GG, Drappa J, Wang L, Yoo S, et al. Anifrolumab, an anti-interferon-alpha receptor monoclonal antibody, in moderate-to-severe systemic lupus erythematosus. Arthritis Rheumatol. 2017:69(2):376-86.

31. de Jong TD, Vosslamber S, Mantel E, de Ridder S, Wesseling JG, van der Pouw Kraan TC, Leurs C, Hegen H, Deisenhammer F, Killestein J, et al. Physiological evidence for diversification of IFNalpha- and IFNbeta-mediated response programs in different autoimmune diseases. Arthritis Res Ther. 2016:18:49.

\section{Submit your next manuscript to BioMed Central and we will help you at every step:}

- We accept pre-submission inquiries

- Our selector tool helps you to find the most relevant journal

- We provide round the clock customer support

- Convenient online submission

- Thorough peer review

- Inclusion in PubMed and all major indexing services

- Maximum visibility for your research

Submit your manuscript at www.biomedcentral.com/submit
) Biomed Central 